EXTENDED REPORT

\title{
Risks of solid cancers in patients with rheumatoid arthritis and after treatment with tumour necrosis factor antagonists
}

\author{
J Askling, C M Fored, L Brandt, E Baecklund, L Bertilsson, N Feltelius, L Cöster, \\ P Geborek, L T Jacobsson, S Lindblad, J Lysholm, S Rantapää-Dahlqvist, T Saxne, \\ L Klareskog
}

See end of article for authors' affiliations

Correspondence to: Dr J Askling, Clinical Epidemiology Unit M9:01, Karolinska University Hospital Solna, SE-171 76 Stockholm, Sweden johan.askling@medks.ki.se

Accepted 6 April 2005 Published Online First 13 April 2005

Background: Existing studies of solid cancers in rheumatoid arthritis (RA) reflect cancer morbidity up until the early 1990s in prevalent cohorts admitted to hospital during the 1980s.

Objective: To depict the cancer pattern of contemporary patients with RA, from updated risk data from prevalent and incident RA populations. To understand the risk of solid cancer after tumour necrosis factor (TNF) treatment by obtaining cancer data from cohorts treated in routine care rather than trials.

Methods: A population based study of three RA cohorts (one prevalent, admitted to hospital 1990-2003 $(n=53$ 067), one incident, diagnosed 1995-2003 ( $n=3703)$, and one treated with TNF antagonists 1999-2003 ( $\mathrm{n}=4160))$, which were linked with Swedish nationwide cancer and census registers and followed up for cancer occurrence through 2003.

Results: With 3379 observed cancers, the prevalent RA cohort was at marginally increased overall risk of solid cancer, with 20-50\% increased risks for smoke related cancers and $+70 \%$ increased risk for nonmelanoma skin cancer, but decreased risk for breast $(-20 \%)$ and colorectal cancer $(-25 \%)$. With 138 cancers, the incident RA cohort displayed a similar cancer pattern apart from non-decreased risks for colorectal cancer. TNF antagonist treated patients displayed solid cancer $(n=67)$ risks largely similar to those of other patients with RA.

Conclusion: The cancer pattern in patients treated with TNF antagonists mirrors those of other contemporary as well as historic RA cohorts. The consistent increase in smoking associated cancers in patients with RA emphasises the potential for smoking cessation as a cancer preventive measure in RA.

$\mathrm{F}$ or rheumatoid arthritis (RA) and other chronic inflammatory diseases subject to prolonged treatment with drugs that influence the immune function, there has always been a concern about whether the inflammatory disease or its treatment might increase the risk of cancer. Whereas most recent such attention has been devoted to haematological malignancies, ${ }^{2}{ }^{2}$ the much more common solid cancers also warrant proper attention. ${ }^{3}$ To correctly assess and relate the risks for cancer in patients with RA, including those treated with new drugs such as tumour necrosis factor (TNF) antagonists, we need data not only from patients treated with such new agents but also data from contemporary patients with RA in general.

Although several studies have previously assessed the relative risk of solid cancers in RA, available data largely reflect the cancer occurrence up until the early 1990s in prevalent cohorts of patients with RA admitted to hospital during the 1970s and 1980s..$^{4-7}$ Thus, it is not certain that the results of these endeavours reflect the burden of RA disease or treatment, or other risk factors for cancer, of contemporary patients with RA. Of necessity, existing studies provide no information on changes in cancer morbidity related to RA treatments introduced during the past one to two decades.

More contemporary data on cancer risk are needed also for the safety evaluation of new antirheumatic drugs. Because cancer is an adverse event which is ill-suited to detection and evaluation in phase III trials-which tend to be short and exclude patients at high risk of cancer $^{8}{ }^{9}$-we need risk data estimated through structured monitoring of patients treated with new drugs such as TNF antagonists in clinical practice.
We also need robust reference rates for cancer in patients with RA not treated with biological agents against which we can compare the reported incidences of cancer in treated series.

To provide contemporary and generalisable data on the relative risk of solid cancers in RA, we followed up one large prevalent cohort and one incident cohort of Swedish patients with RA for cancer occurrence using high quality nationwide cancer and census registers through 2003. To provide data on the risk of solid cancers in patients treated with TNF antagonists in routine care, we followed up a cohort of 4160 patients with RA treated with TNF antagonists for cancer occurrence 1999 through 2003 using the same follow up registers. To aid future evaluation of drug safety, we present age and sex adjusted incidences of solid cancer reflecting RA not treated with biological agents.

\section{SUBJECTS AND METHODS Setting}

Swedish health care is public and population based. Hospital referrals are based on geographical determinants rather than financial capacity or health insurance. Nationwide and population based health and census registers in combination with unique personal identifiers ${ }^{10}$ allow record linkage of register data recorded prospectively since the 1960s, with very few losses to follow up and minimised risk of recall bias.

Abbreviations: NRN, national registration number; NSAID, nonsteroidal anti-inflammatory drug; RA, rheumatoid arthritis; SIR, standardised incidence ratio; TNF, tumour necrosis factor 
Table 1 Characteristics of the three Swedish cohorts of patients with RA

\begin{tabular}{|c|c|c|c|}
\hline & \multicolumn{3}{|c|}{ Rheumatoid arthritis cohorts* } \\
\hline & $\begin{array}{l}\text { Inpatient } \\
\text { Register }\end{array}$ & Early Arthritis & TNF antagonist \\
\hline Overall & 53067 & 3703 & 4160 \\
\hline Men & 15185 & 1114 & 1048 \\
\hline Women & 37882 & 2589 & 3112 \\
\hline \multicolumn{4}{|c|}{ Age at start of follow up (years) } \\
\hline $16-44$ & 4666 & 782 & 950 \\
\hline $45-74$ & 29900 & 2421 & 2986 \\
\hline $75+$ & 18501 & 500 & 224 \\
\hline \multicolumn{4}{|c|}{ Calendar period of entry into cohort } \\
\hline 1964-1979 & 6932 & 0 & 0 \\
\hline 1980-1989 & 11867 & 0 & 0 \\
\hline 1990-1998 & 20898 & 1176 & 11 \\
\hline 1999-2001 & 7667 & 1478 & 2398 \\
\hline $2002-2003$ & 5703 & 1049 & 1751 \\
\hline $\begin{array}{l}\text { Mean (min-max) } \\
\text { follow up (years) }\end{array}$ & $5.6(0-13)$ & $3.6(0-8)$ & $2.3(0-4)$ \\
\hline Person-years & 297102 & 13292 & 9715 \\
\hline DAS28* & & $\begin{array}{l}\text { mean } 3.5 \text {, } \\
\text { median } 3.5\end{array}$ & $\begin{array}{l}\text { mean } 5.5 \\
\text { median } 5.6\end{array}$ \\
\hline $\mathrm{HAQ}^{*}$ & - & $\begin{array}{l}\text { mean } 0.6 \text {, } \\
\text { median } 0.7\end{array}$ & $\begin{array}{l}\text { mean } 1.4, \\
\text { median } 1.4\end{array}$ \\
\hline \multicolumn{4}{|c|}{$\begin{array}{l}\text { Numbers indicate number of patients in each cohort unless otherwise } \\
\text { specified. } \\
\text { *In the Early Arthritis cohort, values (means) refer to status at } 6 \text { months } \\
\text { after diagnosis of RA. In the anti-TNF cohort, values refer to status at the } \\
\text { start of anti-TNF treatment. } \\
\text { DAS28, } 28 \text { joint count Disease Activity Score; HAQ, Health Assessment } \\
\text { Questionnaire. }\end{array}$} \\
\hline
\end{tabular}

\section{The Inpatient Register RA cohort}

The Swedish Inpatient Register contains individual based information on inpatient care county wide since 1964 and nation wide since 1987. ${ }^{11}$ For every hospital discharge, information on diagnoses and surgical procedures is recorded according to the International Classification of Diseases $\left(\mathrm{ICD}^{12}\right)$ versions 7-10. We identified all subjects above 16 years of age ever discharged with a diagnosis of RA (primary or contributory diagnosis) between 1 January 1990 and 31 December 2003. The ICD codes used were 714A-C, 714W (ICD 9), and M05-6 (ICD 10). We excluded subjects who were also discharged with systemic lupus erythematosus, ankylosing spondylitis, or psoriatic arthritis. For each patient, computerised information on the date of first hospital discharge with RA (1964-2003), discharge department, age, sex, and national registration number (NRN, unique to each resident and recorded in all health and census registers ${ }^{10}$ ) was recorded (table 1 ). No information on drug treatment was available. Based on the estimated prevalence of RA in the general population, we calculate that the Inpatient Register RA cohort, as defined in the current paper, encompasses more than $50 \%$ of all patients with RA in Sweden in 2003.

\section{The Early Arthritis RA cohort}

In Sweden, RA is normally diagnosed and followed up by rheumatologists. Centres reporting to the Early Arthritis Register contain a typical mix of small outpatient clinics and larger population based centres. The Early Arthritis Register contains information on subjects with incident $(<1$ year from onset) RA diagnosed at participating centres since the mid-1990s, with a geographically varying $(40-100 \%$ in different regions, overall around $70 \%$ ) but increasing coverage of the estimated number of cases of incident RA. ${ }^{13}$ From this register, we collected information on date of diagnosis of
RA, date of birth, sex, and the NRN for 3703 patients with RA diagnosed from 1995 through 2003 (table 1).

\section{The TNF antagonist cohort of patients with RA}

Within the context of a continuing Swedish structured postmarketing surveillance programme we assembled a cohort of 4160 patients with RA treated with etanercept, infliximab, or adalimumab between 1999 and 2003 (table 1). Details and patient identification methods have been described elsewhere. $^{14}$ In brief, patients were identified through the Swedish Medical Products Agency in collaboration with the Swedish Society for Rheumatology, and through regional surveillance programmes of patients treated with TNF antagonists. A rough estimation from sales statistics suggests that at least $80 \%$ of all patients with RA treated with TNF antagonists in Sweden are included in this register. For each patient, we collected information on date of birth, sex, NRN, type of TNF antagonist, and date of treatment start and discontinuation (table 1 ).

\section{Register linkages and follow up}

Through linkage (of all subjects, using the NRN as linkage key) to the Swedish Cancer Register 1964-2003,15 we collected information on all registered solid malignancies, including the date of diagnosis. Reporting to this registry is mandatory for clinicians and pathologists, resulting in a completeness of around 99\%. ${ }^{15}{ }^{16}$ Only malignant (rather than, for example, atypical) lesions are registered. Nonmelanoma skin cancer excludes basal cell cancer, which is not reported. Through linkage to the Cause of Death Register 1964-2003 and to the Register of Population and Population Changes 1969-2003, we collected information on marital status, and vital status, including date of death and date of emigration until 31 December 2003.

\section{Statistics}

We used standardised incidence ratios (SIRs, the ratio of the observed and expected numbers of cancers) as measures of relative risk. Expected numbers were calculated by multiplying sex-, age-, and calendar period-specific person-years of follow up with corresponding rates from the entire Swedish population. To avoid bias from misdiagnosis and selection for admission to hospital due to an incipient malignancy, we excluded observed and expected cancers during the first year of follow up in the Inpatient Register RA cohort, and stratified all cohorts by time of follow up. Ninety five per cent confidence intervals were calculated assuming a Poisson distribution of the observed cases. Trends were evaluated using Poisson regression. Because more than $80 \%$ of all observation time in the TNF antagonist cohort represented time during treatment, we present data based on the total follow up time. Sixty nine per cent of the TNF antagonist cohort had been admitted to hospital for their RA, and 27\% of the Early Arthritis cohort had been admitted to hospital for their RA before 31 December 2003.

\section{RESULTS \\ Relative risk of cancer in the prevalent Inpatient Register RA cohort 1990-2003}

Based on 3379 observed cases of solid cancer, patients in the Inpatient Register RA cohort were at a minimally increased overall risk of solid cancer ( SIR $=1.05,95 \%$ CI 1.01 to 1.08 ; table 2$)$. The overall relative risk was 1.19 (95\% CI 1.13 to $1.26, \mathrm{n}=1311)$ among men and 0.97 (95\% CI 0.93 to 1.02 , $\mathrm{n}=2068$ ) among women. Much of this sex difference was explained by a reduced occurrence of breast cancer ( $\mathrm{SIR}=0.83,95 \%$ CI 0.76 to $0.91, \mathrm{n}=471$ ) but a risk of prostate cancer close to the expected ( $\mathrm{SIR}=0.98,95 \%$ CI 0.89 to $1.09, \mathrm{n}=390$ ). 
Table 2 Relative risk of solid cancer including 95\% confidence intervals (CI) in each of three Swedish cohorts of patients with RA

\begin{tabular}{|c|c|c|c|c|c|c|}
\hline \multirow[b]{2}{*}{ Site (ICD) } & \multicolumn{2}{|c|}{ Inpatient Register RA cohort ${ }^{*}$} & \multicolumn{2}{|c|}{ Early arthritis RA cohort } & \multicolumn{2}{|c|}{ TNF antagonist RA cohort } \\
\hline & No & $\operatorname{SIR}(95 \% \mathrm{CI})$ & No & $\operatorname{SIR}(95 \% \mathrm{CI})$ & No & $\operatorname{SIR}(95 \% \mathrm{CI})$ \\
\hline All solid† (140-199) & 3379 & $1.05(1.01$ to 1.08$)$ & 138 & $1.1(0.9$ to 1.3$)$ & 67 & $0.9(0.7$ to 1.2$)$ \\
\hline Oropharyngeal (140-148) & 54 & 1.02 (0.76 to 1.33$)$ & 1 & $0.5(0.0$ to 2.7$)$ & 0 & $0.0(0.0$ to 3.0$)$ \\
\hline Oesophagus (150) & 36 & 1.32 (0.93 to 1.83 ) & 3 & $2.8(0.6$ to 8.2$)$ & 0 & $0.0(0.0$ to 7.0$)$ \\
\hline Stomach (151) & 102 & $1.10(0.89$ to 1.33$)$ & 2 & $0.7(0.08$ to 2.5$)$ & 0 & $0.0(0.0$ to 2.7$)$ \\
\hline Small intestine (152) & 20 & $1.22(0.75$ to 1.89$)$ & 1 & $1.7(0.04$ to 9.4$)$ & 0 & $0.0(0.0$ to 11$)$ \\
\hline Colorectal $(153+154)$ & 342 & $0.74(0.66$ to 0.82$)$ & 18 & $1.1(0.7$ to 1.8$)$ & 10 & $1.2(0.6$ to 2.3$)$ \\
\hline Hepatobiliary (155-156) & 103 & $1.15(0.94$ to 1.40$)$ & 5 & $1.9(0.6$ to 4.3$)$ & 1 & $0.7(0.0$ to 4.1$)$ \\
\hline Pancreas (157) & 79 & $0.93(0.74$ to 1.16$)$ & 3 & $1.1(0.2$ to 3.2$)$ & 0 & $0.0(0.0$ to 2.4$)$ \\
\hline Larynx (161) & 13 & 1.19 (0.63 to 2.04$)$ & 0 & $0.0(0.0$ to 7.5$)$ & 1 & $4.0(0.1$ to 22$)$ \\
\hline Lung (162) & 330 & $1.48(1.33$ to 1.65$)$ & 23 & $2.4(1.5$ to 3.6$)$ & 10 & $1.8(0.9$ to 3.3$)$ \\
\hline Breast (170) & 471 & $0.83(0.76$ to 0.91$)$ & 13 & $0.6(0.3$ to 0.1 .0$)$ & 8 & $0.4(0.2$ to 0.9$)$ \\
\hline Cervix (171) & 33 & $1.03(0.71$ to 1.45$)$ & 1 & $0.8(0.02$ to 4.3$)$ & 1 & $1.0(0.0$ to 5.8$)$ \\
\hline Uterine corpus (172) & 84 & $0.60(0.48$ to 0.75$)$ & 1 & $0.2(0.01$ to 1.1$)$ & 2 & $0.6(0.0$ to 2.1$)$ \\
\hline Prostate (177) & 390 & $0.98(0.89$ to 1.09$)$ & 32 & $1.6(1.1$ to 2.3$)$ & 8 & $1.0(0.4$ to 2.0$)$ \\
\hline Testis (178) & 1 & $0.60(0.02$ to 3.37$)$ & 1 & $7.9(0.2$ to 44$)$ & 0 & $0.0(0.0$ to 34$)$ \\
\hline Kidney (180) & 118 & $1.46(1.21$ to 1.75$)$ & 2 & $0.7(0.08$ to 2.5$)$ & 1 & $0.6(0.0$ to 3.5$)$ \\
\hline Urinary bladder (181) & 179 & $1.14(0.98$ to 1.32$)$ & 8 & $1.3(0.6$ to 2.6$)$ & 1 & $0.4(0.0$ to 2.0$)$ \\
\hline Melanoma (190) & 120 & $1.19(0.99$ to 1.42$)$ & 4 & $0.9(0.2$ to 2.2$)$ & 1 & $0.3(0.0$ to 1.8$)$ \\
\hline Non-melanoma skin (191) & 374 & $1.66(1.50$ to 1.84$)$ & 5 & $0.7(0.2$ to 1.6$)$ & 11 & $3.6(1.8$ to 6.5$)$ \\
\hline Brain (193) & 78 & $1.12(0.89$ to 1.40$)$ & 0 & $0.00(0.0$ to 1.2$)$ & 4 & $1.8(0.5$ to 4.6$)$ \\
\hline Connective tissue (197) & 28 & $1.42(0.95$ to 2.06$)$ & 0 & $0.00(0.0$ to 5.1$)$ & 0 & 0.0 (0.0 to 9.2$)$ \\
\hline
\end{tabular}

Follow up from 1990 (or entry into cohort, if later) until 31 December 2003. Relative risk estimated comparing each cohort with the general Swedish population and adjusting for age, sex, and calendar period.

${ }^{*}$ Cancers occurring during first 365 days after entry into cohort are excluded; ttotal solid exceeds sum of site-specific cancers, as only major sites are displayed.

Gastrointestinal cancer risk was marginally reduced ( $\mathrm{SIR}=0.85,95 \%$ CI 0.78 to $0.93, \mathrm{n}=554$ ), made up by a decreased risk of colorectal cancer ( SIR $=0.74,95 \%$ CI 0.66 to $0.82, \mathrm{n}=342$ ), which tended to decrease with increasing time of follow up ( $p$ for trend $=0.01$; table 3 ). Respiratory tract cancers, essentially lung cancers, were more common than expected $(\mathrm{SIR}=1.48,95 \%$ CI 1.33 to $1.65, \mathrm{n}=330)$. The occurrence of non-melanoma skin cancer ( SIR $=1.66,95 \%$ CI 1.50 to $1.84, \mathrm{n}=374$ ) was also increased, and increased with increasing time of follow up ( $\mathrm{p}$ for trend $=0.001$; table 3 ). A modestly increased occurrence of melanomas, kidney and bladder cancers was also noted (table 3). Age- and sexspecific incidences of selected solid cancer sites are tabulated in the appendix.

\section{Relative risk of cancer in the Early Arthritis cohort 1995-2003}

Overall, we observed 138 solid cancers in this cohort $(\mathrm{SIR}=1.1,95 \%$ CI 0.9 to 1.3$)$, with a non-increased risk in women ( $\mathrm{SIR}=0.87,95 \%$ CI 0.67 to $1.11, \mathrm{n}=64$ ) and an increased risk among men ( $\mathrm{SIR}=1.42,95 \%$ CI 1.12 to 1.79 , $n=74$ ). The sex difference was largely due to increased (prostate cancer, SIR $=1.6$ ) and decreased (breast cancer,
SIR $=0.6)$ risks for sex-specific cancers (table 2 ). Lung cancer occurred more often than expected $(S I R=2.4)$. When stratified by time since diagnosis of RA, the increased overall occurrence of cancer was confined to the first year after diagnosis of RA, and partly explained by prostate cancers diagnosed during this period (table 4).

\section{Relative risk of cancer in patients with RA treated with TNF antagonists 1999-2003}

We observed a total of 67 solid cancers in the TNF antagonist treated cohort ( $\mathrm{SIR}=0.9,95 \% \mathrm{CI} 0.7$ to 1.2 ). The relative risk of solid cancer was non-significantly reduced among women ( $\mathrm{SIR}=0.87,95 \%$ CI 0.63 to $1.16, \mathrm{n}=45)$ but 1.06 (95\% CI 0.67 to $1.61, \mathrm{n}=22$ ) among men, and varied little with time since the start of treatment (table 4). Contrary to the other RA cohorts, we did not observe any decreased occurrence of colorectal cancer $(\mathrm{SIR}=1.2)$, but similar to the other RA cohorts, we noted an increased occurrence of lung cancer $(\mathrm{SIR}=1.8)$, a markedly reduced occurrence of breast cancer ( $S I R=0.4)$, but an increased occurrence of non-melanoma skin cancer $(\operatorname{SIR}=3.6$; table 2$)$. Because of low numbers, trends in site-specific relative risks were difficult to evaluate (table 4).

Table 3 Numbers of observed cancers, relative risks (95\% confidence intervals (CI)) of solid cancer in the Swedish Inpatient Register RA cohort, stratified by time since the start of follow up

\begin{tabular}{|c|c|c|c|c|c|c|}
\hline \multirow[b]{2}{*}{ Cancer site (ICD) } & \multicolumn{2}{|c|}{$1-4$ years } & \multicolumn{2}{|c|}{$5-9$ years } & \multicolumn{2}{|c|}{$10+$ years } \\
\hline & No & SIR $(95 \% \mathrm{CI})$ & No & $\operatorname{SIR}(95 \% \mathrm{CI})$ & No & $\operatorname{SIR}(95 \% \mathrm{Cl})$ \\
\hline All solid & 1131 & $1.04(0.98$ to 1.10$)$ & 899 & $1.08(1.01$ to 1.15$)$ & 1349 & $1.04(0.98$ to 1.09$)$ \\
\hline Colorectal & 135 & $0.87(0.73$ to 1.03$)$ & 87 & $0.73(0.59$ to 0.90$)$ & 120 & $0.64(0.53$ to 0.77$)$ \\
\hline Hepatobiliary & 41 & $1.36(0.98$ to 1.85$)$ & 29 & $1.27(0.85$ to 1.82$)$ & 33 & $0.91(0.62$ to 1.27$)$ \\
\hline Lung & 104 & $1.39(1.14$ to 1.69$)$ & 106 & $1.85(1.51$ to 2.23$)$ & 120 & 1.32 ( 1.10 to 1.58$)$ \\
\hline Breast & 137 & $0.77(0.65$ to 0.92$)$ & 120 & 0.82 (0.68 to 0.98$)$ & 214 & $0.88(0.76$ to 1.00$)$ \\
\hline Prostate & 137 & $0.90(0.75$ to 1.06$)$ & 103 & $0.98(0.80$ to 1.19$)$ & 150 & $1.08(0.91$ to 1.26$)$ \\
\hline Melanoma & 31 & 0.91 (0.62 to 1.29 ) & 32 & $1.22(0.83$ to 1.72$)$ & 57 & $1.42(1.07$ to 1.83$)$ \\
\hline Non-melanoma skin & 112 & 1.39 (1.15 to 1.68$)$ & 88 & $1.49(1.20$ to 1.84$)$ & 174 & 2.04 (1.74 to 2.36$)$ \\
\hline
\end{tabular}

Study period from 1990 (or entry into cohort, if later) until 31 December 2003. Relative risk compared with the general Swedish population adjusting for age, sex, and calendar period. 
Table 4 Relative risks -including 95\% confidence intervals $(\mathrm{CI})$ and number of observed cancers-of solid cancers in the Early Arthritis RA cohort and in the TNF antagonist RA cohort, stratified by time since diagnosis of RA (Early Arthritis RA cohort) and time since start of TNF antagonist treatment (TNF antagonist RA cohort), respectively

\begin{tabular}{|c|c|c|c|c|c|c|}
\hline \multirow[b]{2}{*}{ Cancer site (ICD) } & \multicolumn{2}{|c|}{$<1$ year } & \multicolumn{2}{|c|}{$1-2$ years } & \multicolumn{2}{|c|}{$3+$ years } \\
\hline & No & $\operatorname{SIR}(95 \% \mathrm{Cl})$ & No & $\operatorname{SIR}(95 \% \mathrm{Cl})$ & No & $\operatorname{SIR}(95 \% \mathrm{Cl})$ \\
\hline \multicolumn{7}{|l|}{ Early arthritis } \\
\hline All solid & 44 & $1.4(1.1$ to 1.9$)$ & 55 & $1.1(0.9$ to 1.5$)$ & 39 & 0.8 (0.6 to 1.2$)$ \\
\hline Colorectal & 5 & $1.3(0.4$ to 3.1$)$ & 8 & $1.3(0.6$ to 2.5$)$ & 5 & $0.8(0.3$ to 2.0$)$ \\
\hline Hepatobiliary & 0 & $0.0(0.0$ to 5.5$)$ & 3 & $2.8(0.6$ to 8.3$)$ & 2 & $2.1(0.3$ to 7.5$)$ \\
\hline Lung & 9 & 3.8 (1.8 to 7.3$)$ & 6 & $1.6(0.6$ to 3.5$)$ & 8 & $2.3(1.0$ to 4.6$)$ \\
\hline Breast & 4 & $0.7(0.2$ to 1.8$)$ & 6 & $0.7(0.2$ to 1.5$)$ & 3 & $0.4(0.1$ to 1.0$)$ \\
\hline Prostate & 11 & 2.3 (1.2 to 4.1$)$ & 12 & $1.5(0.8$ to 2.7$)$ & 9 & $1.2(0.6$ to 2.3$)$ \\
\hline Melanoma & 1 & $0.9(0.0$ to 4.9$)$ & 3 & $1.7(0.4$ to 4.9$)$ & & 0.0 (0.0 to 2.2$)$ \\
\hline Non-melanoma skin & 0 & $0.0(0.0$ to 2.2$)$ & 2 & $0.7(0.1$ to 2.5$)$ & 3 & $1.0(0.2$ to 2.9$)$ \\
\hline \multicolumn{7}{|l|}{ TNF antagonist } \\
\hline All solid & 25 & $1.0(0.6$ to 1.5$)$ & 32 & 0.9 (0.6 to 1.3$)$ & 10 & $0.8(0.4$ to 1.6$)$ \\
\hline Colorectal & 2 & $0.7(0.1$ to 2.6$)$ & 8 & $2.0(0.8$ to 4.0$)$ & 0 & $0.0(0.0$ to 2.8$)$ \\
\hline Hepatobiliary & 0 & $0.0(0.0$ to 7.7$)$ & 1 & $1.5(0.0$ to 8.4$)$ & 0 & $0.0(0.0$ to 17$)$ \\
\hline Lung & 5 & $2.6(0.8$ to 6.0$)$ & 3 & $1.1(0.2$ to 3.2$)$ & 2 & $2.3(0.3$ to 8.2$)$ \\
\hline Breast & 4 & $0.6(0.2$ to 1.6$)$ & 3 & $0.3(0.1$ to 1.0$)$ & 1 & $0.3(0.0$ to 1.9$)$ \\
\hline Prostate & 3 & $1.1(0.2$ to 3.3$)$ & 3 & $0.7(0.1$ to 2.2$)$ & 2 & $1.5(0.2$ to 5.4$)$ \\
\hline Melanoma & 0 & $0.0(0.0$ to 3.5$)$ & 1 & $0.7(0.0$ to 3.8$)$ & 0 & $0.0(0.0$ to 7.7$)$ \\
\hline Non-melanoma skin & 5 & $4.9(1.6$ to 11$)$ & 5 & 3.3 (1.1 to 7.8 ) & 1 & $2.0(0.1$ to 11$)$ \\
\hline
\end{tabular}

\section{DISCUSSION}

To provide contemporary data on the risk of solid cancers in RA, we followed up the hitherto largest cohort of prevalent patients-admitted to hospital with RA during the 1990sfor cancer occurrence through 2003. To assess the generalisability of these cancer risks, we also followed up a recent cohort of incident patients with RA not necessarily admitted to hospital. In doing so, we made several important observations. Firstly, we confirmed the non-increased overall solid cancer risk in (female) RA and its composition of increased and decreased site-specific risks. Secondly, we found that the cancer patterns in the two cohorts were largely similar, with the exception that recently diagnosed patients with RA were neither at decreased risk of colorectal cancer nor at increased risk of non-melanoma skin cancer, but at particularly increased occurrence of cancer often detected during routine medical examinations (prostate cancer). To assess the safety of TNF antagonists we followed up a large cohort of patients with RA treated with TNF antagonists in routine care, but found (with the possible exception of nonmelanoma skin cancer) no conspicuous occurrence of solid cancers. Finally, to aid future evaluation of drug safety we presented incidence rates for solid cancers in RA.

Current knowledge of the risk of solid cancers in RA essentially rests upon data from historical cohorts of prevalent patients with RA who have been identified in hospital discharge registers and followed up for cancer occurrence in other health registers. ${ }^{4-7}$ Although the results of these studies have been internally consistent, their generalisability to current patients and clinical practice, and their ability to serve as reference rates (only relative risks have been presented) in the safety evaluation of new drugs must be judged in light of the following.

Firstly, the RA cohorts identified may neither reflect the burden of RA disease or treatment experience nor the distribution of other risk factors for cancer (for example, smoking among women) that characterise patients of today. Instead, the typical patient with RA has been identified on the basis of admission to hospital for RA dating 15 or more years back in time (1977-1987 in Mellemkjaer et al, ${ }^{6}$ 19651983 in Gridley et al, ${ }^{4}$ 1981-1996 in Thomas et al, ${ }^{7}$ and from the 1960s until 1990 in Kauppi et al and MyllykangasLuosujarvi et $a l^{5}{ }^{17}$ ).
Secondly, the follow up of these cohorts has, with few exceptions, ${ }^{7}$ ended before the early 1990s, so there is little information on any changes in cancer risk related to the substantial changes in average RA disease status or treatment implemented during the past 10-20 years.

Thirdly, because these studies employed the same methodology and included a qualitatively similar subset of patients with RA, their consistent results come as little surprise, but leave unanswered the question of whether patients with RA ever-admitted to hospital differ from those never admitted to hospital. Likewise, entry into the cohorts in these studies was set to the date of the first discharge with RA, which may not necessarily equate to the date of diagnosis of RA. Although there are studies using other designs and follow up methods, ${ }^{18-23}$ these have often been limited to a few hundred patients diagnosed and/or followed up before the 1990s.

It follows from the above that we need not only updated cancer risks from large scale RA cohorts but also more information on how cancer risks in such prevalent cohorts compare with those of recent, incident-and largely outpatient-RA cohorts.

Across all cohorts followed up-and as in previous studies-we noted a difference between the sexes, with higher overall relative risks among men than women. This difference between men and women was largely explained by a reduced risk of female breast cancer. This reduced breast cancer risk is not only consistent with some previous reports $^{4}{ }^{6}$ but also with recent data suggesting an inverse association between non-steroidal anti-inflammatory drug (NSAID) use (but not acetaminophen) and breast cancer. ${ }^{24}$ The non-increased risk of prostate cancer in the prevalent RA cohort in combination with the increased occurrence in early follow up in the incident cohort suggests that the latter risk may be due to increased detection rather than a true RA related risk increase.

In the Inpatient Register RA cohort, we not only observed an increased risk for non-melanoma skin cancer but also an increasing relative risk with increasing follow up time, which may explain the non-increased risk in the incident RA cohort, in which the average disease duration was shorter. The $70 \%$ increased risk in our study is higher than the $20 \%$ increased risk reported by Gridley et al who followed up patients with 
RA identified in the Swedish Inpatient Register during the 1960s up until the 1980s, ${ }^{4}$ suggesting increasing risks also by calendar period. Because immune suppression is an established risk factor for non-melanoma skin cancer, a causal association with an increasingly aggressive approach in the treatment of RA cannot be ruled out. The $25 \%$ reduced risk of colorectal cancer in the Inpatient Register RA cohort not only corroborates previous studies, but may be an effect of NSAID use. $^{25}$

In the Early Arthritis Register cohort, there was a nonsignificantly increased $(+13 \%)$ colorectal cancer risk. Apart from poor precision because of the small number of observed colorectal cancers in this cohort $(\mathrm{n}=18)$, possible explanations for the seemingly divergent risks include detection bias (colorectal cancer is often detected during investigation for anaemia or gastrointestinal bleeding, both of which are common medical problems in RA), insufficient time for NSAIDs to exert any protective effect, or a lower use of NSAIDs in the incident cohort.

Smoking is a risk factor for (seropositive) $\mathrm{RA}^{26}{ }^{26}$ and a risk factor for a wide array of cancers (for example, respiratory tract cancer, kidney, and urinary bladder cancer), which also displayed increased risks in our cohorts. However, like colorectal cancer, part of the immediate risk increase for lung cancer may be related to detection bias such as through chest $x$ ray examinations, which at least in Sweden are common in the investigation for RA. It remains clear however, that stopping smoking would provide substantial cancer prevention in RA.

Information about the safety of new drugs can be derived from several sources: clinical trials offer a built-in comparator group, but the patients under study often differ substantially from those encountered in routine care. Patients at the highest risk of cancer-for example, those with anaemia for unknown reason, pathological liver enzyme tests, history of cancer, or precancerous lesion, are often excluded, ${ }^{27}$ and the trials are often too short to detect insidious adverse events like cancers. Open extensions of the treated arm of clinical trials may, if carefully monitored, provide good data on the occurrence of rare outcomes, but require readily available reference rates against which the experiences in the treated population (which is still a selected group) can be compared. Post-marketing surveillance which relies on physicians' spontaneous reporting may result in underreporting and difficulties in determining the person-time experience.

Structured monitoring programmes of patients treated within the framework of routine care as in our study offer patients who have been less selected, and-if supplemented by qualitatively similar reference rates-provide a unique possibility of assessing the spectrum of comorbidity associated with treatment.

For TNF antagonists, analyses of clinical trials have shown an increased occurrence of malignant lymphomas, but inconspicuous risks for solid cancers, including a significant deficit of lung cancers, which may indicate patient selection. ${ }^{2}$ Using regional data, ${ }^{28}$ and data from a previous national linkage, ${ }^{29}$ we have previously reported the occurrence of solid cancer after treatment with TNF antagonists. Although the number of observed cases was small $\left(n=11^{28}\right.$ and $n=16^{29}$, both sets are included in the 67 cases observed in the current study), the relative risk for solid cancer overall in our three approaches is similar. Although still based on modest number of cancers, and although we cannot exclude the possibility that patients with a lower risk for cancer are directed towards treatment with TNF antagonists, our results suggest that TNF antagonists as actually used in practice are not associated with a cancer pattern that differs from that of other patients with RA (although the non-decreased colorectal cancer occurrence may be a concern). Prolonged follow up is necessary in order to detect or rule out cancer risks for which the induction time exceeds the currently available follow up times.

\section{ACKNOWLEDGEMENTS}

We gratefully acknowledge the following centres and their Swedish RA register/ARTIS representatives for allowing us to use their data: Yngve Adolfsson, Sunderby Hospital, Luleå; Ewa Berglin, Norrland's University Hospital, Umeå; Torgny Smedby, Östersund County Hospital; Rüdi Götze, Sundsvall County Hospital; Anna-Carin Holmqvist, Hudiksvall's Hospital; Sven Tegmark, Gävle County Hospital; Jörgen Lysholm, Falu lasarett, Falun; Solveig Gustafsson, Karlstad's Central Hospital; Eva Baecklund, Akademiska Hospital, Uppsala; Rolf Oding, Västerås Hospital; Per Salomonsson, University Hospital, Örebro; Birgitta Nordmark, Karolinska University Hospital, Solna; Ingiäld Hafström, Karolinska University Hospital, Huddinge; Göran Lindahl, Danderyd's Hospital, Stockholm; Gun Sandahl, Queen Sophia Hospital, Stockholm; Martin Mousa, Visby lasarett, Visby; Anders Lindblad, Visby Privat, Visby; Åke Thörner, Mälarsjukhuset, Eskilstuna; Lars Cöster, University Hospital, Linköping; Sören Transö, County Hospital Ryhov, Jönköping; Olle Svernell, Västervik's Hospital; Claudia Jacobs, Oskarshamn's Hospital; Bengt Lindell, Kalmar County Hospital; Maria Söderlin, Växjö’s CentralHospital; Olof Börjesson, Växjö Privat; Göran Kvist, Centrallasarettet Borås; Karin Svensson, Kärnsjukhuset, Skövde; Tomas Torstenson, Uddevalla Hospital; Ingeli Andreasson, Göteborg privat; Lennart Bertilsson, Sahlgrenska University Hospital, Gothenburg; Tore Saxne, University Hospital in Lund; Miriam Karlsson, Lasarettet Trelleborg; Annika Teleman, Spenshult, Oskarström; Catharina Keller, Helsingborg's Lasarett; Astrid Schröder, Ängelholm's Hospital; Jan Theander, Kristianstad's Central Hospital; Christina Book, MAS University Hospital, Malmö. Financial support for the Early Arthritis Register was provided by the Swedish National Board of Health and Welfare.

Financial support for this study was obtained from the Swedish Cancer Society, from the insurance company AFA, and from WyethAyerst, Schering-Plough, Abbott Immunology, and Bristol Myer Squibb. The investigators were in charge of, and solely responsible for, all data collection, analysis and writing of the manuscript, without any constraints exerted from the agencies or companies that helped to sponsor the study. The South Swedish Anti-TNF Register

Table 5 Age- and sex-specific incidences (per 100 000) of solid cancers in the Swedish Inpatient Register RA cohort 19902003

\begin{tabular}{|c|c|c|c|c|c|c|}
\hline \multirow[b]{2}{*}{ Site (ICD-7) } & \multicolumn{3}{|l|}{ Men } & \multicolumn{3}{|l|}{ Women } \\
\hline & $0-49$ & $50-74$ & $75+$ & $0-49$ & $50-74$ & $75+$ \\
\hline All solid (140-199) & $182(97$ to 312$)$ & 1633 (1510 to 1768$)$ & 3239 (2996 to 3497 ) & 297 (232 to 375$)$ & 1005 (945 to 1067$)$ & 1346 (1261 to 1467$)$ \\
\hline Colorectal (153-154) & $14(0$ to 78$)$ & $137(103$ to 179$)$ & $296(226$ to 381$)$ & $29(12$ to 60$)$ & 87 (71 to 108$)$ & 184 (153 to 219$)$ \\
\hline Hepatobiliary (155-156) & $0(0$ to 52$)$ & $33(18$ to 56$)$ & 74 (42 to 122$)$ & $0(0$ to 15$)$ & 31 (22 to 44$)$ & $60(43$ to 81$)$ \\
\hline Lung (162) & 0 (0 to 52$)$ & 254 (207 to 310 ) & 271 (205 to 354$)$ & 4. $(0$ to 23$)$ & 105 (87 to 127) & $89(68$ to 115$)$ \\
\hline Breast $(170)$ & $0(0$ to 52$)$ & $2.5(0$ to 14$)$ & $4.9(0.0$ to 27$)$ & $125(85$ to 180$)$ & 267 (237 to 300$)$ & 223 (190 to 262 ) \\
\hline Prostate (177) & 28 (3.4 to 102$)$ & 493 (426 to 568 ) & 958 (827 to 1103$)$ & - & - & - \\
\hline Melanoma (190) & 28 (3.4 to 102$)$ & 33 (18 to 57$)$ & $103(64$ to 159$)$ & 37 (17 to 72$)$ & 34 (24 to 48$)$ & 55 (39 to 76$)$ \\
\hline Non-melanoma skin (191) & $0(0$ to 52$)$ & 152 (117 to 197$)$ & 572 (473 to 687) & $4.2(0$ to 23$)$ & 57 (44 to 74$)$ & 197 (165 to 234 ) \\
\hline
\end{tabular}


has received funding from King Gustav V, Österlund and Kock Foundations, and from Reumatikerförbundet.

\section{Authors' affiliations}

J Askling, C M Fored, L Brandt, Clinical Epidemiology Unit, Department of Medicine, Karolinska University Hospital, Stockholm, Sweden J Askling, N Feltelius, S Lindblad, L Klareskog, Rheumatology Unit, Department of Medicine, Karolinska University Hospital, Stockholm, Sweden

E Baecklund, Department of Rheumatology, Uppsala University Hospital, Uppsala, Sweden

L Bertilsson, Department of Rheumatology, Sahlgrenska University Hospital, Gothenburg, Sweden

N Feltelius, Medical Products Agency, Uppsala, Sweden

L Cöster, Department of Rheumatology, Linköping University Hospital, Linköping, Sweden

P Geborek, T Saxne, Department of Rheumatology, Lund University Hospital, Lund, Sweden

LT Jacobsson, Department of Rheumatology, Malmö University Hospital, Malmö, Sweden

J Lysholm, Department of Rheumatology, Falu County Hospital, Falun, Sweden

S Rantapää-Dahlqvist, Department of Rheumatology, University

Hospital, Umeå, Sweden

\section{APPENDIX}

Table 5 shows age- and sex-specific incidences of solid cancers in the Swedish Inpatient Register RA cohort 19902003.

\section{REFERENCES}

1 Wolfe F, Michaud K. Lymphoma in rheumatoid arthritis: the effect of methotrexate and anti-tumor necrosis factor therapy in 18,572 patients. Arthritis Rheum 2004:50:1740-51.

2 Safety update on TNF-alpha antagonists. In: US Food and Drug Administration, Arthritis Drugs Advisory Committee, 2003.

3 Symmons DP, Silman AJ. Anti-tumor necrosis factor alpha therapy and the risk of lymphoma in rheumatoid arthritis: no clear answer. Arthritis Rheum 2004;50:1703-6.

4 Gridley G, McLaughlin JK, Ekbom A, Klareskog L, Adami HO, Hacker DG, et al. Incidence of cancer among patients with rheumatoid arthritis. J Natl Cancer Inst 1993:85:307-1 1

5 Kauppi M, Pukkala E, Isomaki $\mathrm{H}$. Elevated incidence of hematologic malignancies in patients with Sjögren's syndrome compared with patients with rheumatoid arthritis (Finland). Cancer Causes Control 1997;8:201-4.

6 Mellemkjaer L, Linet MS, Gridley G, Frisch M, Moller H, Olsen JH. Rheumatoid arthritis and cancer risk. Eur J Cancer 1996:32A:1753-7.

7 Thomas E, Brewster DH, Black RJ, Macfarlane GJ. Risk of malignancy among patients with rheumatic conditions. Int J Cancer 2000;88:497-502.

8 Pincus T, Sokka T. Clinical trials in rheumatic diseases: designs and limitations. Rheum Dis Clin North Am 2004;30:701-24, v-vi.

9 Lipsky PE, van der Heijde DM, St Clair EW, Furst DE, Breedveld FC, Kalden JR, et al. Infliximab and methotrexate in the treatment of rheumatoid arthritis.
Anti-Tumor Necrosis Factor Trial in Rheumatoid Arthritis with Concomitant Therapy Study Group. N Engl J Med 2000;343:1594-602.

10 Lunde AS, Lundeborg S, Lettenstrom GS, Thygesen L, Huebner J. The personnumber systems of Sweden, Norway, Denmark, and Israel. Vital Health Stat 2, 1980;2:1-59.

11 Patientregistret 1987-1996 Kvalitet och innehåll. Stockholm: Epidemiologiskt Centrum, Socialstyrelsen, 1998.

12 International Classification of Diseases. Geneva: World Health Organisation 1955.

13 Soderlin MK, Borjesson O, Kautiainen H, Skogh T, Leirisalo-Repo M. Annual incidence of inflammatory joint diseases in a population based study in southern Sweden. Ann Rheum Dis 2002;61:911-15.

14 Feltelius N, Fored CM, Blomqvist P, Bertilsson L, Geborek P, Jacobsson LT, et al. Results from a nationwide post marketing cohort study of patients in Sweden treated with etanercept. Ann Rheum Dis 2005;64:246-52.

15 Cancer incidence in Sweden. Stockholm: National Board of Health and Welfare 2001

16 Mattsson B, Wallgren A. Completeness of the Swedish Cancer Register. Nonnotified cancer cases recorded on death certificates in 1978. Acta Radiol Oncol 1984;23:305-13

17 Myllykangas-Luosujarvi R, Aho K, Isomaki H. Mortality from cancer in patients with rheumatoid arthritis. Scand J Rheumatol 1995;24:76-8.

18 Symmons DP. Neoplasms of the immune system in rheumatoid arthritis. Am J Med 1985;78:22-8.

19 Bendix G, Bjelle A, Holmberg E. Cancer morbidity in rheumatoid arthritis patients treated with Proresid or parenteral gold. Scand J Rheumatol 1995:24:79-84.

20 Cibere J, Sibley J, Haga M. Rheumatoid arthritis and the risk of malignancy. Arthritis Rheum 1997;40:1580-6.

21 Speerstra F, Boerbooms AM, van de Putte LB, van Beusekom HJ, Kruijsen MW, Vandenbroucke JP. Side-effects of azathioprine treatment in rheumatoid arthritis: analysis of 10 years of experience. Ann Rheum Dis 1982:41(suppl 1):37-9.

22 van den Borne BE, Landewe RB, Houkes I, Schild F, van der Heyden PC, Hazes JM, et al. No increased risk of malignancies and mortality in cyclosporin A-treated patients with rheumatoid arthritis. Arthritis Rheum 1998:41:1930-7.

23 Lewis P, Hazleman BL, Hanka R, Roberts S. Cause of death in patients with rheumatoid arthritis with particular reference to azathioprine. Ann Rheum Dis 1980;39:457-61

24 Terry MB, Gammon MD, Zhang FF, Tawfik H, Teitelbaum SL, Britton JA, et al. Association of frequency and duration of aspirin use and hormone receptor status with breast cancer risk. JAMA 2004;291:2433-40.

25 Sorensen HT, Friis S, Norgard B, Mellemkjaer L, Blot WJ, McLaughlin JK, et al. Risk of cancer in a large cohort of nonaspirin NSAID users: a populationbased study. Br J Cancer 2003;88:1687-92.

26 Stolt $\mathrm{P}$, Bengtsson C, Nordmark B, Lindblad S, Lundberg I, Klareskog L, et al. Quantification of the influence of cigarette smoking on rheumatoid arthritis: results from a population based case-control study, using incident cases. Ann Rheum Dis 2003;62:835-41.

27 Maini R, St Clair EW, Breedveld F, Furst D, Kalden J, Weisman M, et al. Infliximab (chimeric anti-tumour necrosis factor alpha monoclonal antibody) versus placebo in rheumatoid arthritis patients receiving concomitant methotrexate: a randomised phase III trial. ATTRACT Study Group. Lancet 1999;354:1932-9.

28 Geborek P, Bladstrom A, Turesson C, Gulfe A, Petersson I, Saxne T, et al. TNF blockers do not increase overall tumour risk in patients with rheumatoid arthritis, but may be associated with increased risk of lymphomas. Ann Rheum Dis 2005;64:699-703.

29 Askling J, Brandt L, Bertilsson L, Feltelius N, Fored M, Geborek P, et al. A national database for comorbidity in RA to evaulate drug-safety. Solid cancers in RA and following anti-TNF treatment. Ann Rheum Dis 2004;63(suppl I):85. 